\title{
Impact of Urban Microclimate on the Energy Performance of Riad-type Buildings
}

\author{
Adnane M'Saouri El Bat ${ }^{1}$, Zaid Romani ${ }^{2}$, Emmanuel Bozonnet ${ }^{3}$, Abdeslam Draoui $^{1}$ \\ ${ }^{1}$ Team of Heat Transfer \& Energetic FST of Tangier, Abdelmalek Essaâdi University, Tangier, \\ Morocco. \\ ${ }^{2}$ National School of Architecture, Tetouan, Morocco. \\ ${ }^{3}$ LaSIE, La Rochelle University, La Rochelle, France.
}

\begin{abstract}
In this study a simplified approach for urban microclimate modelling by using TRNSYS 17 software has been developed and validated. This approach has the advantage to model the microclimatic phenomena in order to consider them in a dynamic building thermal simulation software without going through time-consuming CFD calculations, and with a satisfactory accuracy for thermal and energy evaluation. This approach is used to determine the microclimate impact on Riad's thermal behavior. The obtained results show that the estimated energy performances of Riad by only dynamic thermal simulation tools are deviating in relation to the developed approach.
\end{abstract}

\section{Introduction}

Nowadays, it has become essential for living in cities to build new buildings able to adapt their environment with less energy consumed and meet the requirements of a sustainable development. Thus, the building sector remains one of the main contributors that have an impact on the environment due to their high level of energy consumption, especially as the vast majority of the energy used in buildings comes from fossil fuel resources.

On the other hand, climatic conditions are the main determinants on building's energy demand since they interact with their immediate surroundings. More precisely, the urban microclimate resulting from a complex interaction between different physical phenomena (air temperature, humidity, wind flow and solar radiation) and the elements those constitute the city such as urban development, building materials and human activity. In this respect, several studies have shown that urban microclimate has an impact on the building energy consumption (Bozonnet, Belarbi, and Allard 2007; Allegrini, Dorer, and Carmeliet 2012; Vallati et al. 2015).

In this context, the engineers, the architects and the designers must be able to design buildings with highenergy efficiency, taking into account the microclimate impact. For this purpose, several models have been developed in the literature, among them CitySim (Robinson et al. 2009), Solene microclimat (Musy et al. 2015) and EnviBate (Gros, Bozonnet, and Inard 2014). These models are generally detailed, but are complex to use (high computation time, use of several software).
However, these studies evaluated the interaction between the building and only its external microclimate, which is not the case for other building types, namely Riad (buildings with courtyard). In architectural design, the courtyard represents one of the two major building models known in history whose characteristics depend on the surroundings and a region's culture. We are faced with a common conception that has been applied for thousands of years in different regions the world, mainly in houses (Edwards et al. 2006). Today, courtyards are also still utilized worldwide, and are a traditional component of construction in Asia, Middle East, South America and Mediterranean countries (Xu et al. 2018).

In the literature, many researchers have studied climatic aspects of courtyards by examining their microclimatic performance, while a limited number the studies examine the thermal function of the courtyard (Zamani, Heidari, and Hanachi 2018). In addition, due to the complex interactions between the microclimatic and thermal functions of the courtyard, the simultaneous simulation of thermal conditions of indoor and outdoor spaces remains inevitable (Zamani, Heidari, and Hanachi 2018).

In this sense, it appears advantageous to develop a more complete approach to evaluate the thermal and microclimatic (indoor and outdoor) performance of courtyard and their energy consumption.

In this work, we present a modelling approach to assess the microclimate impact on the Riad's energy performance. For this reason, a new method integrated in the TRNSYS 17 software has been developed that allows the description of thermal aeraulic and radiative phenomena not only in the Riad's, but also at the microclimatic scale of the near environment to the Riad or the neighbourhood.

In this approach, the radiative model is based on the Gebhart factor (Gebhart 1961) to calculate radiative exchanges and inter-reflections as well as the solar radiation distribution coefficients. While the aeraulic model is based on the Harman model (Harman, Barlow, and Belcher 2004) and the Soulhac model (Soulhac, Perkins, and Salizzoni 2008) which allows to take into account the effects of dominant winds. To evaluate the validity of the developed method, a comparison between the obtained and the experimental results is presented. Thereafter, this model is then used to determine the 
microclimate impact generated by an urban canyon with two different aspect ratio ( $\mathrm{H} / \mathrm{W}=1$ and 3) on the Riad's energy needs.

\section{Method}

\section{Thermoradiative model}

In this study, the proposed thermoradiative model is developed using TRNSYS 17 software. On this software, the heat conduction transfers are modelled by the transfer functions. For modelling convective heat transfer, two possibilities are available, one to set the value of the convective heat transfer coefficient and the other to use specific correlations. For radiative exchanges, TRNSYS distinguishes between short-wavelength (CLO) and longwavelength (GLO) exchanges. These exchanges are modelled differently for indoor and outdoor surfaces. More specifically, solar irradiation on outdoor surfaces is considered as a gain while the longwave radiation is treated as a heat loss to the cold sky. A 3D radiation model that takes account of multiple reflections is provided but only for interior zones.

However, a street canyon and the courtyard are characterized by the phenomenon of radiative trapping which affects the energy balance and is materialized by the multiple reflections of radiation on the different surfaces. In this model, given that TRNSYS software cannot model the urban microclimate, the street canyon and courtyard are modeled by an atrium with an open ceiling and virtual edges, which are represented by an open window. This choice allows the software to consider the canyon and the courtyard as an internal thermal zone in which the effects of radiative inter-reflections are evaluated.

\section{Solar radiation modelling}

For interior surfaces, direct and diffuse solar radiation are not treated in the same way by TRNSYS software. The user can specify the distribution of direct radiation. In order to model direct solar radiation, either a standard model or a detailed model can be used.

In our model, we have chosen to use the standard model since the detailed model does not allow us to model the direct radiation entering an area through the adjacent windows. Thus, the standard model allows the solar radiation distribution even when it crosses through adjacent windows in more than two passages.

The calculation of the coefficients of solar radiation distribution was carried out in a way to the solar radiation is distributed over all surfaces with the exception of the window where it entered. In the case of the surfaces constituting the canyon or the inner course, these coefficients are determined by using formula (1) which depend on the shadow surface. For this purpose, we have developed and programmed a calculation code in Python language that is implemented on TRNSYS.

$$
G S_{j}=\frac{A_{j}-A_{s j}}{\sum_{i}\left(A_{i}-A_{s i}\right)}
$$

Where: $G S_{j}$ is the coefficient of solar radiation distribution, $A_{j}$ is the surface of the considered wall and $A_{s j}$ is the surface of the shadow carried on the considered wall.

In order to determine the $A_{s j}$ surface, we propose a method based on a very simple calculation. This method depends on the sun position that is specified by two solar angles: solar azimuth $\left(\theta_{s}\right)$ solar zenith $\left(\varphi_{s}\right)$. Expressions (2) and (3) are used to calculate $A_{s i}$ for walls and road respectively.

$$
\begin{aligned}
& A_{s i}=\frac{1}{2}\left|\sum_{i=0}^{n-1}\left(z_{i} y_{i+1}-z_{i+1} y_{i}\right)\right| \\
& A_{s i}=\frac{1}{2}\left|\sum_{i=0}^{n-1}\left(x_{i} y_{i+1}-x_{i+1} y_{i}\right)\right|
\end{aligned}
$$

With $x_{i}, y_{i}, z_{i}$ are the coordinates of the projected shadow, and $l_{i}$ is the projection of this shadow on the xy plane.

$$
\begin{gathered}
x_{i}=l_{i} \sin \theta_{s} \\
y_{i}=l_{i} \cos \theta_{s} \\
l_{i}=\frac{H}{\tan e} \\
\mathrm{e}=90^{\circ}-\varphi_{\mathrm{s}}
\end{gathered}
$$

Where $z_{i}$ is determined in function of $x_{i}$.

Figure (1) illustrates the projection of shadow on the ground.

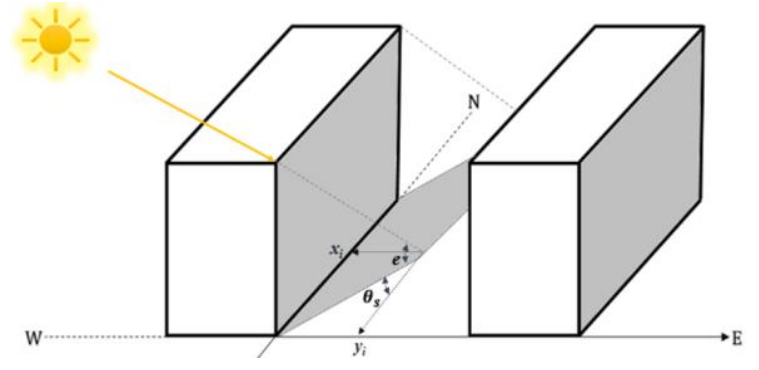

Figure $1:$ Schematization of the shadow projection on the ground.

In the case of the direct solar radiation distribution through the canyon adjacent windows, we have adopted the method proposed by Chatziangelidis and Bouris (2009). The total quantity of solar radiation entering through a window i $\left(Q_{d i r, i}\right)$ is distributed among the other five internal surfaces according to the view factors theory $\left(F_{i \rightarrow j}\right)$ given by the formula (8).

$$
Q_{\text {dir }, i}=\sum_{i}^{n} F_{i \rightarrow j} Q_{\text {dir }, i}
$$

If the total direct radiation entering the zone is defined as follows:

$$
Q_{d i r, t o t}=\sum_{j=1}^{6} G S_{j} \sum_{i=1}^{n} Q_{d i r, i}
$$

Knowing that the direct radiation entering a zone is given by the following formula:

$$
Q_{d i r, t o t}=\sum_{i=1}^{n} Q_{d i r, i}
$$

As a result, the solar radiation distribution coefficient can be given as follows:

$$
G S_{j}=\frac{\sum_{i}^{n} F_{i \rightarrow j} Q_{d i r, i}}{\sum_{i}^{n} Q_{d i r, i}}
$$

After determining the solar radiation distribution of the considered surfaces, the quantity of direct solar energy 
absorbed by these surfaces is obtained by the product of the absorption coefficient $\alpha_{s}$ and the solar radiation distribution coefficient. About the reflected radiation, we used a diffuse radiation detailed model of TRNSYS based on Gebhart's factors (Gebhart 1961; Klein et al. 2010) which allows to include the multi-reflections of solar radiation. These factors are calculated by equation (12).

$$
G_{i, k}=\left(I-F_{i, k} \sigma_{k}\right)^{-1} F_{i, k}\left(I-F_{i, k} \rho_{k}\right)
$$

Where $\boldsymbol{G}$ is the Gebhart factor matrix, i is one of the surfaces exchanging with surface $\mathrm{k}, \boldsymbol{I}$ is the identity matrix, $\boldsymbol{F}$ is the view factor matrix and $\boldsymbol{\rho}$ is the surface reflectivity.

The solar radiation fluxes in closed volumes are calculated as follows:

$$
Q_{c, k}=A_{k}\left(1-\alpha_{k}\right) I_{c, k}+\sum_{i=1}^{n} A_{i} G_{i, k} \alpha_{i} I_{c, i}
$$

With $\mathrm{n}$ is the surfaces number, $Q_{c}$ is the solar radiation flux, $A$ is the surface area, $\alpha$ the surface albedo and $I_{c}$ is the solar radiation flux on surface $\mathrm{k}$.

\section{Thermal radiation modelling}

The modelling of thermal radiation for inside surfaces is based on Gebhart's factors (Gebhart 1961) :

$$
\begin{gathered}
Q_{g, k}=A_{k} \varepsilon_{k} \sigma T_{k}^{4}-\sum_{i=1}^{n} A_{i} \varepsilon_{i} \sigma T_{i}^{4} G_{i, k} \\
G_{i, k}=\left(I-F_{i, k} \sigma_{k}\right)^{-1} F_{i, k} \varepsilon_{k}
\end{gathered}
$$

Where $Q_{g}$ is the thermal radiation flux, $\varepsilon$ is the emissivity, $\sigma$ is the Stefan-Boltzmann constant and $T$ is the surfaces temperature.

For outside surfaces, the solar radiation received is considered as a heat gain. However, the thermal radiation is considered as a heat loss to the sky and calculated by the following formula:

$$
\begin{gathered}
Q_{g, k}=A_{k} \varepsilon_{k} \sigma\left(T_{k}^{4}-T_{s k y f}^{4}\right) \\
T_{s k y f}=\left(1-f_{\text {sky }}\right) T_{a}+f_{s k y} T_{s k y}
\end{gathered}
$$

Where $f_{\text {sky }}$ is the fraction of the sky seen by surface $\mathrm{k}, T_{a}$ is the ambient temperature and $T_{s k y}$ is the fictive sky temperature.

As previously mentioned, the canyon is modelled by an atrium with an open ceiling and virtual borders. However, the virtual layer must not interfere with the heat transfer between the canyon and the outside environment. The solar radiation is transmitted to the canyon surfaces and the courtyards because this layer is transparent. However, it is an obstacle to the thermal radiation exchange between the canyon surfaces and the sky. Therefore, it was necessary that its temperature be equal to the sky temperature.

However, TRNSYS 17 software does not give the possibility to assign a temperature to any surface but it allows to impose an internal or external gain. In this context, we decided to follow this method to make the temperature of this layer equal to the temperature of the sky. This was achieved by imposing an energy balance, so the sum of the losses to the virtual surface be equals the loss to the sky.
Finally, the shading of adjacent buildings and the exchange of shortwave and longwave radiation between the different canyon buildings and the courtyards surfaces can be precisely modelled.

\section{Soil model}

The modelling of ground heat transfers with is based on NF EN ISO 13370 standard and TRNSYS type 77. The latter represents the sinusoidal evolution of the temperature over the year. This model permits the calculation of the temperature profile for undisturbed ground at different depths based on the Kusuda model (Kusuda and Achenbach 1965). The cyclic evolution of the ground temperature $T_{s z}$, at a depth $z$, is expressed as a function of the mean surface temperature $T_{s u, a v g}$ for the period studied using the following formula :

$T_{s z}(t)=T_{\text {su,avg }}+\Delta T_{\text {su }} \cdot e^{-z \sqrt{\frac{\pi}{a_{s o l} \Delta t}}} \cos \left(\frac{2 \pi t}{\Delta t}-z \cdot \sqrt{\frac{\pi}{a_{s o l} \cdot \Delta t}}\right)(18)$

With $\Delta T_{s u}$ is the amplitude of surface temperature variation over the period considered, $\Delta t$ is the period considered and $a_{s o l}$ is the thermal diffusivity of the ground.

\section{Aeraulic model of a street canyon}

The urban airflow depends essentially on the streets geometrical characteristics, building wall roughness and wind speed and its direction. This airflow influences the heat flow generated by the air of the interior spaces and the convective exchanges on the building envelope's external surface. In the following, the aeraulic model is described in detail, knowing that model developed in Python programming language was coupled to the multizone building model component (Type 56) by creating a new TRNSYS component, to calculate the street and courtyard mass balance.

\section{Longitudinal flow modeling}

In street canyons, the airflow generated by an outside wind blowing in any direction relative to the street axis. This flow consists of a recirculation in the plane transverse to the street and a longitudinal flow along the street.

The longitudinal wind velocity component $U_{\text {canyon }}$ is modelled by the Soulhac model (Soulhac, Perkins, and Salizzoni 2008). The main hypothesis of this model is that longitudinal flow results from a balance between entrainment by the external flow and friction on the street sides. By applying these assumptions, the $U_{\text {canyon }}$ velocity can be calculated as follows:

$U_{\text {canyon }}=U_{H} \cos (\varphi) \frac{\delta_{i}^{2}}{H W}\left[\frac{2 \sqrt{2}}{C}(1-\beta)\left(1-\frac{C^{2}}{3}+\frac{C^{4}}{45}\right)+\right.$ $\left.\beta \frac{2 \alpha-3}{\alpha}+\left(\frac{W}{\delta_{i}}-2\right) \frac{\alpha-1}{\alpha}\right]$

Where:

$$
\begin{gathered}
\alpha=\ln \left(\frac{\delta_{i}}{z_{0, \text { bluid }}}\right) \\
\beta=e^{\frac{C}{\sqrt{2}}\left(1-\frac{H}{\delta_{i}}\right)}
\end{gathered}
$$




$$
U_{H}=U_{*} \sqrt{\frac{\pi}{\sqrt{2} k^{2} C}\left[Y_{0}(C)-\frac{J_{0}(C) Y_{1}(C)}{J_{1}(C)}\right]}
$$

$C$ is the solution for $\frac{Z_{0, \text { build }}}{\delta_{i}}=\frac{2}{C} \exp \left[\frac{\pi}{2} \frac{Y_{1}(C)}{J_{1}(C)}-\gamma\right]$

We define

$$
\delta_{i}=\min \left(H ; \frac{W}{2}\right)
$$

Where $J_{0}, J_{1}, Y_{0}$ and $Y_{1}$ are Bessel functions, $u *$ is the friction velocity, $\varphi$ is the external wind direction with respect to the street axis, $H$ and $W$ are the street height and width, respectively, and, zo,build is the aerodynamic roughness of canyon walls.

To calculate the mean wind speed $u(z)$ at a height $z$, above a surface can be estimated using Tennekes' formula (25) (Tennekes 1973).

$$
u(z)=\frac{u_{*}}{k} \ln \left(\frac{z-d}{z_{0}}\right)
$$

Where $u *$ is the friction velocity, $k=0.4$ is von Karman's constant, $d$ is the displacement length and $z_{0}$ is the roughness length of the urban canopy considered.

\section{Transverse flow modeling}

In this study, the transverse flow in street canyon and courtyard have been modelled by using the model developed by Harman et al (2004). This model decomposes the street canyon (or courtyard) into two separate regions according to its geometry: a recirculation region and a ventilated region (Figure 2).

The recirculation region is approximated by a trapezoidal cross-section (Malet 1983) of a length $\left(L_{r}\right)$ that depends on the turbulence of the boundary layer and the geometric shape of the buildings and that varies between $2 \mathrm{H}$ and $3.5 H$ according to the authors. In this model, the length $L_{r}$ has been fixed at $3 H$.

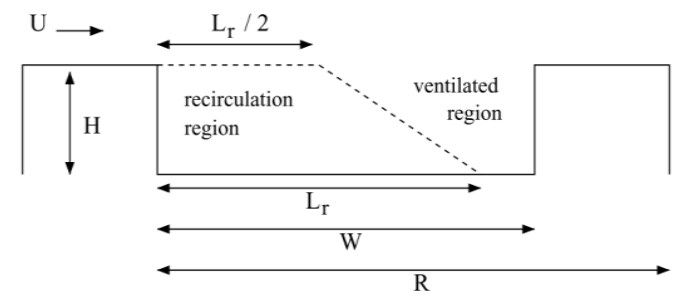

Figure 2 : Schematic of the circulation region and the ventilated region in a street canyon (Harman, Barlow, and Belcher 2004).

The flows in the ventilated and recirculation region are due to the air jet generated by the air detachment behind the upstream roof. According to Harman et al (2004), these air flows develop boundary layers along the canyon street facets as a function of the size of the recirculation region.

For determining the jet velocity profile, Harman et al (2004) proposed a logarithmic profile that describes the effect of the aerodynamic resistance exerted by the surfaces on the jet using the formula (26) (Figure 3):

$$
u_{i}(x)=\frac{u\left(z_{r}\right) \sin (\varphi)}{b} e^{-\alpha_{1} \frac{L_{s} e}{H}} \int_{a}^{a+b} e^{-\alpha_{2} \frac{x}{H}} d x
$$

With: $u(z r)$ is the velocity at a reference height $z_{r}, \alpha_{1}=0.9$, $\alpha_{2}=0.15 \times \max (1 ; 1.5 \mathrm{~h} / \mathrm{d}), a$ is the total distance travelled by the jet to the start of the facet in question, and $b$ is the length of the facet.

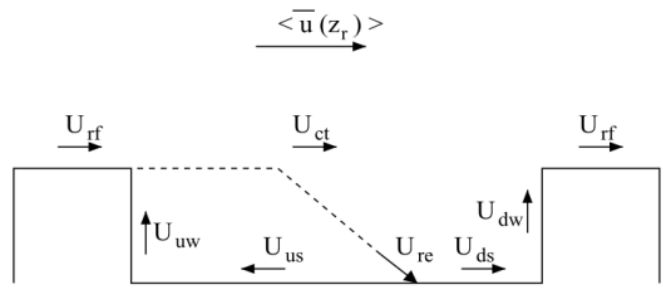

Figure 3 : Schematic of the Transverse Wind Velocities in a canyon street (Harman, Barlow, and Belcher 2004).

The $u_{r f}$ and $u_{c t}$ velocities are calculated as a function of the wind velocity at a reference height $u\left(z_{r}\right)$ by extending the logarithmic profile of the inertial zone (formula 27 and formula 28).

$$
\begin{gathered}
\frac{u_{r f}}{u\left(z_{r}\right)}=\frac{\ln \left(\frac{H+\delta_{r f}-d_{0}}{z_{0}}\right)}{\ln \left(\frac{z_{r}-d_{0}}{z_{0}}\right)} \\
\frac{u_{c t}}{u\left(z_{r}\right)}=\frac{\ln \left(\frac{H-d_{0}}{z_{0}}\right)}{\ln \left(\frac{z_{r}-d_{0}}{z_{0}}\right)}
\end{gathered}
$$

With: $\delta_{r f}=\min \left[0.1(R-W), z_{r}-H\right]$

In the case of the ventilated region, the average velocities on the facets $u_{r e}, u_{d s}$ and $u_{d w}$ are calculated as follows:

$$
\begin{gathered}
u_{r e}=u_{c t} e^{\frac{-\alpha_{1} L_{s e}}{H}} \\
u_{d s}=\left(\frac{u_{r e}}{W-L_{r}}\right) \int_{0}^{W-L_{r}} e^{\frac{-\alpha_{2} x}{H}} d x \\
u_{d w}=\left(\frac{u_{r e}}{H}\right) \int_{W-L_{r}}^{W-L_{r}+H} e^{\frac{-\alpha_{2} x}{H}} d x
\end{gathered}
$$

Where $L_{s e}$ is the length of the sloping edge of the recirculation region.

\section{Determination of the convective heat transfer coefficient}

The value of the heat transfer coefficient for building façades is assumed to be constant for the inside of the building $\left(6.1 \mathrm{~W} / \mathrm{m}^{2} \mathrm{~K}\right.$ for the ceiling, $1.6 \mathrm{~W} / \mathrm{m}^{2} \mathrm{~K}$ for the floor and $4.1 \mathrm{~W} / \mathrm{m}^{2} \mathrm{~K}$ for the walls). For the outside, we calculated the convective heat transfer coefficient using the Hagishima and Tanimoto (2003) correlation given by formulae (32) and (33).

For Horizontal surfaces:

$$
h_{c, e x t}=2.28 V_{R}+8.18
$$

For vertical surfaces:

$$
h_{c, e x t}=10.21 V_{l o c}+4.47
$$

Concerning the calculation of $V_{R}$ and $V_{l o c}$ speeds [m/s], we propose a new method. This method takes into account the variations of the building type (high, medium or low), the orientation of the surface, the shelter effects by other buildings as well as the roughness of the surfaces. So, these velocities can be calculated based on the following formulas:

$$
\begin{gathered}
V_{R}=u_{r f} \\
V_{\text {loc }}=\sqrt{U_{r u e}^{2}+U_{r e}^{2}}
\end{gathered}
$$




\section{Comparison with experimental results}

In order to evaluate the validity of the theoretical model that we have developed, a comparative study with experimental ClimaBat measurements has been performed.

\section{The ClimaBat experiment}

The experimental model "ClimaBat" represents an urban scene on a scale of 1:10 composed of five parallel and identical rectangular buildings when the canyon facades are oriented to east and west (Figure 4) (Doya, Bozonnet, and Allard 2012)(Djedjig, Bozonnet, and Belarbi 2016)(Djedjig, Bozonnet, and Belarbi 2015). Each building is formed by the juxtaposition of 3 rainwater collection tanks. The tanks, made of concrete, are $1.26 \mathrm{~m}$ high, $1.13 \mathrm{~m}$ wide and $1.68 \mathrm{~m}$ long. The regular spacing of the buildings forms four street canyons with an aspect ratio of Width/Height equal to 0.8 . The roadway is equivalent to a light pedestrian area. It consists of $4 \mathrm{~cm}$ thick gravel concrete slabs placed on a bed of sand and 80 $\mathrm{cm}$ gravel. Concerning meteorological data, a TMY2 file was created from experimental measurements during the period from 01/02/2012 to 13/03/2012.

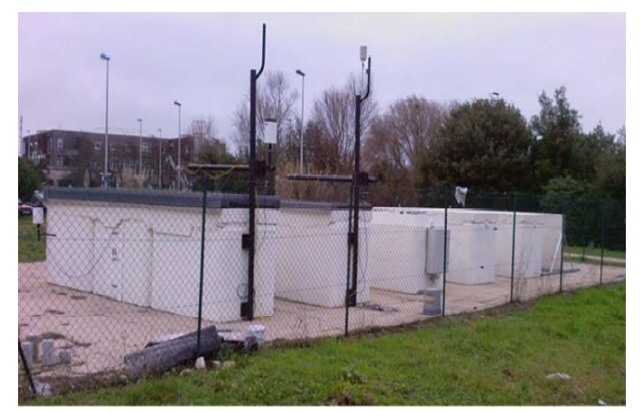

Figure 4 : ClimaBat experimental platform (Djedjig 2013).

The table (1) summarizes the thermo-physical properties of the materials used in the ClimaBat model:

Table 1: Thermophysical properties of building and soil materials (Doya, Bozonnet, and Allard 2012; Djedjig,

Bozonnet, and Belarbi 2016, 2015).

\begin{tabular}{|c|c|c|}
\cline { 2 - 3 } \multicolumn{1}{c|}{} & Concrete & Roadway \\
\hline Thickness $[\mathrm{cm}]$ & 4.5 & 10 \\
\hline Conductivity $[\mathrm{W} / \mathrm{mK}]$ & 2.36 & 0.04 \\
\hline Density $\left[\mathrm{kg} / \mathrm{m}^{3}\right]$ & 2150 & 1.25 \\
\hline Heat capacity $[\mathrm{J} / \mathrm{kgK}]$ & 915 & 1000 \\
\hline$\varepsilon$ & 0.9 & 0.9 \\
\hline$\alpha$ & 0.36 & 0.64 \\
\hline
\end{tabular}

\section{Canyon facades comparisons}

The comparison of the results obtained using our theoretical model and ClimaBat experimental results for the estimation of eastern canyon surfaces temperatures shows a good agreement (Figure 5). It can be noted that the results obtained from this comparison are satisfactory since the maximum absolute error does not exceed $3.24^{\circ} \mathrm{C}$. Also, the mean absolute and mean relative errors are respectively $0.86^{\circ} \mathrm{C}$ and $4.49 \%$, the standard deviation is about $20.90^{\circ} \mathrm{C}$. The regression coefficient in this case is greater than 0.9415 (Figure 6).

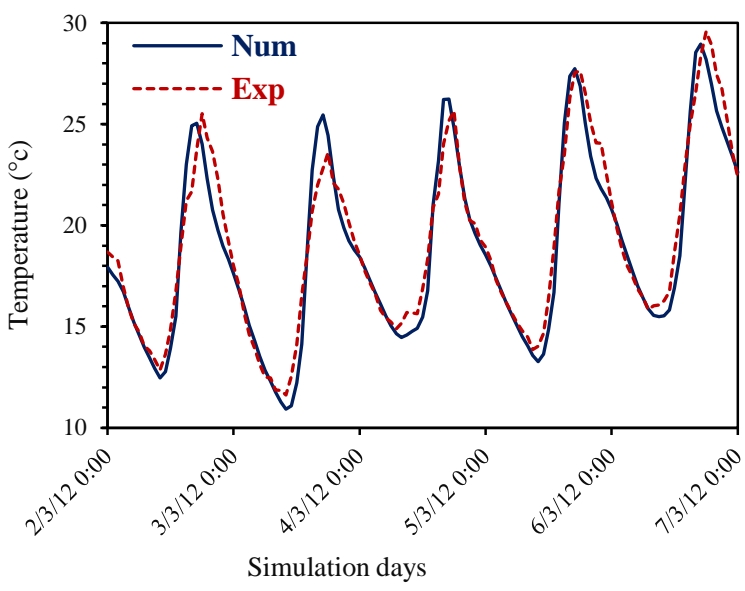

Figure 5 : Temporal variation of Est surfaces temperature.

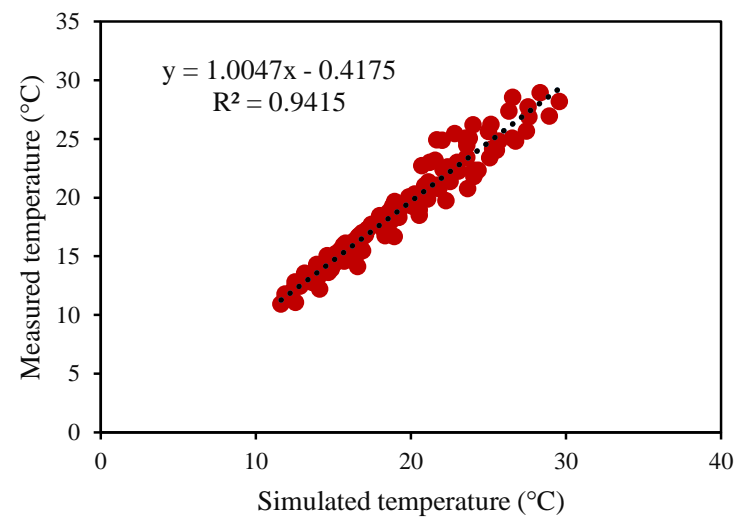

Figure 6: Comparison of simulated and measured temperature values for the East surfaces.

Similarly, to the East surface temperatures, a comparative study was conducted between the numerical and experimental West surface temperatures (Figure 7). In this case, the maximum absolute error is about $2.58^{\circ} \mathrm{C}$ and the mean absolute error is $0.58^{\circ} \mathrm{C}$ and the mean relative error reaches $3.06 \%$, the standard deviation is about $20.88^{\circ} \mathrm{C}$. The regression coefficient $\mathrm{R}^{2}$ is 0.9674 (Figure 8).

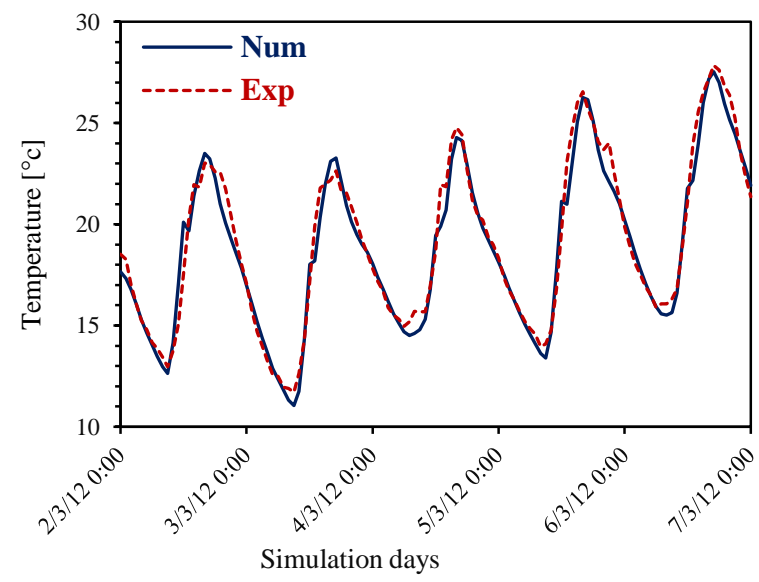

Figure 7 : Temporal variation of the West surfaces temperature. 


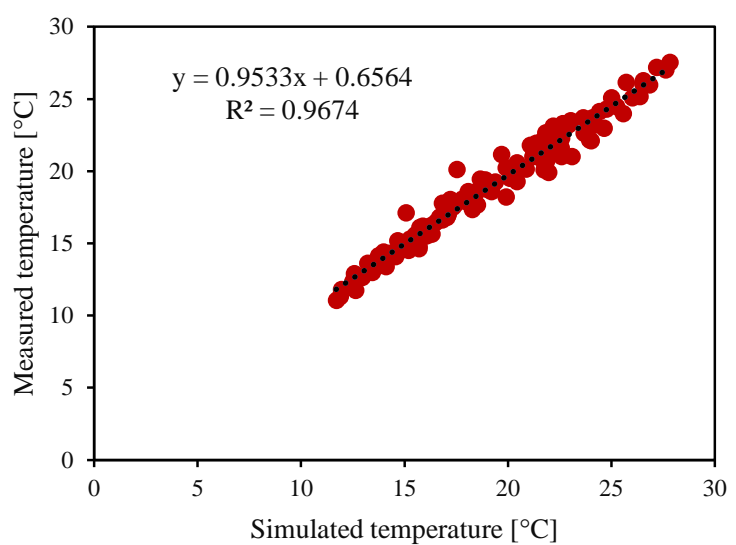

Figure 8 : Comparison of simulated and measured temperature values for the West surfaces.

Based on this comparative study, the microclimatic model developed and the method proposed for calculating the convective heat transfer coefficient provide a very satisfactory and accurate estimate of outdoor surface temperatures and can subsequently be used in the energy modelling of thermal buildings and the urban microclimate.

\section{Riad energy simulation using the model developed}

\section{Description of the Riad studied}

In order to analyze the studied Riad heating and cooling demand, an energy modelling was carried out for three different cases: a stand-alone Riad in an open field by using TRNSYS software only, the same Riad by using the developed approach (SARM) and the same Riad but this time is located in an urban environment with a street canyon in front and behind the considered building.

Street canyons with aspect ratios of 1 and 3 are considered (aspect ratio $H / W$ with $H$ : height of the building, $W$ : street canyon width). Figure 9 depicts the studied Riad surrounded by street canyons with an aspect ratio of 1 . In the set of simulation only one orientation for the street canyon axes was adopted: E-W. The studied street canyon building is surrounded by two other rows of buildings (Figure 9-b), which have the same properties as the studied Riad. The energy demands of these two buildings are not evaluated.

(a)
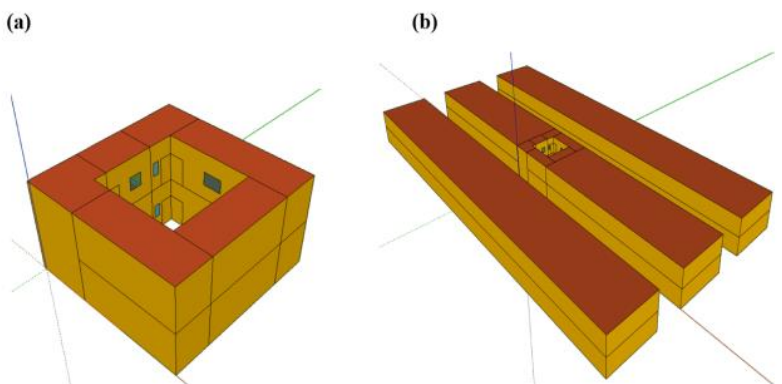

Figure 9: Overview 3d of the Riad (a) and the street canyon $(b)$.
The considered Riad has a total area of $169 \mathrm{~m}^{2}(13 \mathrm{~m}$ of width and $13 \mathrm{~m}$ of length) and the height is of $3.5 \mathrm{~m}$, with $10 \%$ of this area occupied by the courtyard. Concerning the openings, the total area of the window size is $12.2 \mathrm{~m}^{2}$ and the percentage of the façade is about $6.22 \%$. Figure 10 and Table 2 give the description of the Riad model used as a case study.

Table 2: Thermophysical properties of Riad and soil materials.

\begin{tabular}{|c|c|c|c|c|c|}
\hline $\begin{array}{c}\text { Envelope } \\
\text { element }\end{array}$ & Materials & $\begin{array}{c}\text { Thickness } \\
{[\mathrm{cm}]} \\
\end{array}$ & $\begin{array}{c}\lambda \\
{[\mathrm{W} / \mathrm{mK}]}\end{array}$ & $\begin{array}{c}\mathbf{C}_{p} \\
{[\mathbf{J} / \mathbf{k g K}]}\end{array}$ & $\begin{array}{c}\rho \\
{\left[\mathrm{kg} / \mathrm{m}^{3}\right]}\end{array}$ \\
\hline \multirow{5}{*}{$\begin{array}{c}\text { Outside } \\
\text { Wall }\end{array}$} & Cement & 1.5 & 1.15 & 1000 & 1700 \\
\hline & Brick & 7 & 0.3 & 741 & 1200 \\
\hline & Air & 10 & - & 1000 & 1 \\
\hline & Brick & 7 & 0.3 & 741 & 1200 \\
\hline & Cement & 1.5 & 1.15 & 1000 & 1700 \\
\hline \multirow{3}{*}{$\begin{array}{c}\text { Adjacent } \\
\text { Wall }\end{array}$} & Cement & 1.5 & 1.15 & 1000 & 1700 \\
\hline & Brick & 7 & 0.3 & 741 & 1200 \\
\hline & Cement & 1.5 & 1.15 & 1000 & 1700 \\
\hline \multirow{5}{*}{$\begin{array}{c}\text { Roof and } \\
\text { ceiling }\end{array}$} & Tile & 0.7 & 1.4 & 1000 & 2500 \\
\hline & Screed & 1 & 0.42 & 1000 & 1800 \\
\hline & Concrete & 4 & 2.3 & 1000 & 2350 \\
\hline & $\begin{array}{c}\text { hollow } \\
\text { block }\end{array}$ & 16 & 0.6 & 880 & 1000 \\
\hline & Cement & 1.5 & 1.15 & 1000 & 1700 \\
\hline \multirow{3}{*}{$\begin{array}{c}\text { Ground } \\
\text { floor }\end{array}$} & Tile & 0.7 & 1.4 & 1000 & 2500 \\
\hline & Screed & 1 & 0.42 & 1000 & 1800 \\
\hline & Concrete & 20 & 2.5 & 1000 & 2350 \\
\hline \multirow{2}{*}{ Pavement } & Ceramics & 0.7 & 1.4 & 1000 & 2500 \\
\hline & Concrete & 10 & 0.04 & 1000 & 2350 \\
\hline
\end{tabular}

Where: $\lambda$ is the conductivity, $C_{p}$ is the heat capacity and $\rho$ is the density.

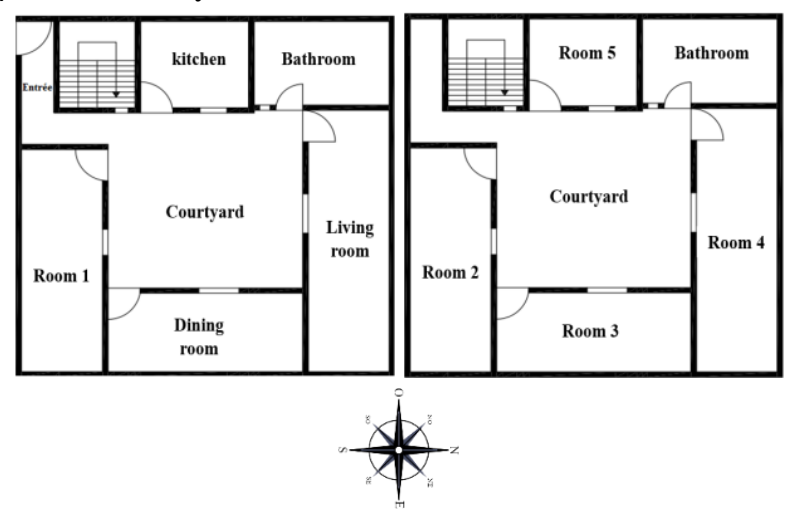

Figure 10 : Ground floor (left) and first floor (right) plans.

The following table shows the glazing characteristics used:

Table 3: Windows characteristics.

\begin{tabular}{|c|c|c|c|c|}
\hline Windows & Material & $\begin{array}{c}\text { Thickness } \\
{[\mathbf{m m}]}\end{array}$ & $\begin{array}{c}\text { U-value } \\
{\left[\mathbf{W} / \mathbf{m}^{2}\right.} \\
\mathbf{K}]\end{array}$ & $\begin{array}{c}\text { G- } \\
\text { value } \\
(\boldsymbol{\%})\end{array}$ \\
\hline $\begin{array}{c}\text { Single } \\
\text { glazing }\end{array}$ & $\begin{array}{c}\text { Ordinary } \\
\text { glass }\end{array}$ & 2.5 & 5.74 & 0.84 \\
\hline
\end{tabular}

Concerning the absorption coefficient, we have adopted 0.6 for walls and roofs and 0.8 for pavements. 
During the modelling, we supposed that the Riad is occupied by five people. The rooms are occupied every day from $22 \mathrm{~h}$ to $7 \mathrm{~h} 30 \mathrm{~min}$. The living room is used for relaxing during the day. It is occupied from $7 \mathrm{~h} 30$ to $8 \mathrm{~h}$, from $13 \mathrm{~h}$ to $18 \mathrm{~h}$ by two people and from $20 \mathrm{~h}$ to $22 \mathrm{~h}$. The kitchen is occupied from $7 \mathrm{~h}$ to $7 \mathrm{~h} 30$, from $12 \mathrm{~h} 30$ to $12 \mathrm{~h}$ and from $18 \mathrm{~h}$ to $19 \mathrm{~h}$ by two people.

The internal gains due to the lighting system are $5 \mathrm{~W} / \mathrm{m}^{2}$ (incandescent lamp). The other appliances that produce the internal loads in the building are presented in the following table:

Table 4 : Specific values of internal gains.

\begin{tabular}{|c|c|c|c|}
\hline Appliance & Area & $\begin{array}{c}\text { Operating } \\
\text { time }\end{array}$ & Power [W] \\
\hline Refrigerator & Kitchen & $24 / 24$ & 125 \\
\hline TV & $\begin{array}{c}\text { Living } \\
\text { room }\end{array}$ & In occupation & 75 \\
\hline $\begin{array}{c}\text { Cooking } \\
\text { appliances }\end{array}$ & Kitchen & In occupation & 200 \\
\hline Computer & Bed-room & In occupation & 100 \\
\hline
\end{tabular}

The ventilation rate is $0.5 \mathrm{vol} / \mathrm{h}$ while the envelope infiltration rate is assumed to be $0.2 \mathrm{vol} / \mathrm{h}$. The cooling and heating temperature set point are respectively $26{ }^{\circ} \mathrm{C}$ and $20^{\circ} \mathrm{C}$. The climatic data taken into account are those of the city of Tangier (Morocco) and they are used as input for the energy simulation of the Riad.

\section{Numerical results}

In this part a presentation and commentary on the results obtained from simulations is provided. They concern the considered urban configurations, namely the stand alone building case modelled by TRNSYS and by the developed approach (SARM) as well as the two cases in which the Riad is located in its urban context (SARM H / W = 1, SARM H / W = 3). Figures 11 and 12 represent heating and cooling energy needs for the different simulation cases.

First, the comparison of the results from TRNSYS and SARM shows that TRNSYS heating and cooling energy needs are $26 \%$ and $24 \%$ higher than those of SARM respectively. This results in the fact that TRNSYS does not take into account the microclimate generated by the courtyard.

Secondly, the comparison between the energy demand of $\mathrm{RM}_{\mathrm{H} / \mathrm{W}=1}$ and $\mathrm{RM}_{\mathrm{H} / \mathrm{W}=3}$ in relation to $\mathrm{SARM}$ shows that the lowest cooling demand (Figure 12) is associated with the $\mathrm{RM}_{\mathrm{H} / \mathrm{W}=3}$ configuration. In fact, in this case, the building is flanked by more narrow canyons, thus being sheltered from direct solar radiation. Since the Riad is closed to the outside, which protects from street heat and noise. As a result, the narrow canyon, preventing solar radiation from entering, provides energy benefits in the summer season.

Similarly, for space heating demands (Figure 11), the results show that the $\mathrm{RM}_{\mathrm{H} / \mathrm{W}=3}$ is the most advantageous configuration. This is due to the radiative trapping phenomenon that is materialized by the multiple interreflections between the canyon surfaces.
Heating energy needs

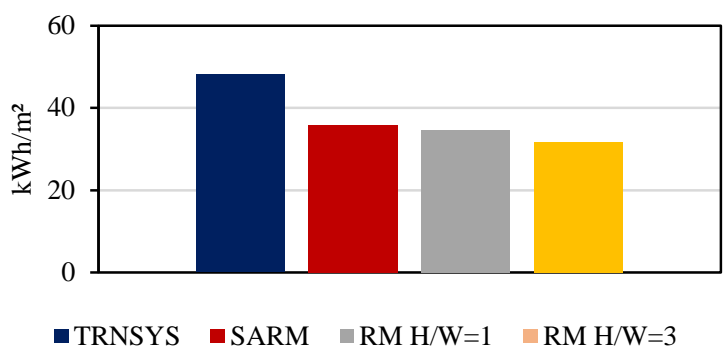

Figure 11: Heating energy needs.

Cooling energy needs

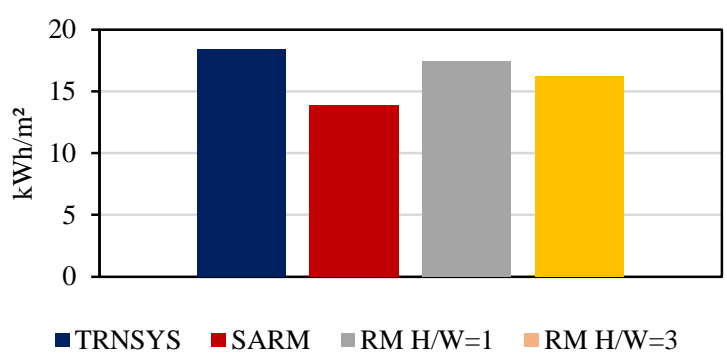

Figure 12 : Cooling energy needs.

\section{Conclusion}

In this study, a simplified approach has been developed using TRNSYS 17 software to assess the impact of urban microclimate on a Riad's energy demand. This approach takes into account the effects of dominant winds, sunshine and inter-reflection.

In order to evaluate the validity of the approach developed, a comparative study between the experimental results and our numerical results has been performed, which showed a good agreement.

Based on the developed method, a comparative study between the energy demand of a stand-alone Riad including and excluding the microclimate generated by the courtyard and for the same Riad located in a street canyon in Tangier has been realized.

First, a comparison between the results obtained by using TRNSYS 17 only and by using the developed approach showed that the estimated demand determined by TRNSYS is overestimated.

Secondly, the results obtained show that the cooling demand for the SARM configuration is lower than $\mathrm{RM}_{\mathrm{H} / \mathrm{W}=1}$ by $25 \%$ and $\mathrm{RM}_{\mathrm{H} / \mathrm{W}=1}$ by $17 \%$ on the one hand, and on the other hand the heating demand for the SARM configuration is high than $\mathrm{RM}_{\mathrm{H} / \mathrm{W}=1}$ by $3 \%$ and $\mathrm{RM} / \mathrm{H}=3$ by $11 \%$. As a consequence, the most advantageous configuration is $\mathrm{RM}_{\mathrm{H} / \mathrm{W}=3}$.

Finally, the results obtained show that the use of this method is interesting for its reduced calculation time compared to CFD calculations with satisfactory accuracy for thermal and energy evaluation. 


\section{References}

Allegrini, Jonas, Viktor Dorer, and Jan Carmeliet. 2012 "Influence of the Urban Microclimate in Street Canyons on the Energy Demand for Space Cooling and Heating of Buildings." Energy and Buildings 55: 823-32. https://doi.org/10.1016/j.enbuild.2012.10.013.

Bozonnet, Emmanuel, Rafik Belarbi, and Francis Allard. 2007. "Thermal Behaviour of Buildings: Modelling the Impact of Urban Heat Island." Journal of Harbin Institute of Technology (New Series) 14 (Sup.): 19-22.

Chatziangelidis, K, and D Bouris. 2009. "Calculation of the Distribution of Incoming Solar Radiation in Enclosures." Applied Thermal Engineering 29 (56):

1096-1105. https://doi.org/10.1016/j.applthermaleng.2008.05.0 26.

Djedjig, Rabah. 2013. "Impacts Des Enveloppes Végétales à l'interface bâTiment Microclimat Urbain."

Djedjig, Rabah, Emmanuel Bozonnet, and Rafik Belarbi. 2015. "Analysis of Thermal Effects of Vegetated Envelopes : Integration of a Validated Model in a Building Energy Simulation Program." Energy \& Buildings 86: 93-103. https://doi.org/10.1016/j.enbuild.2014.09.057.

Djedjig, Rabah, Emmanuel Bozonnet, and Rafik Belarbi. 2016. "Urban Climate Modeling Green Wall Interactions with Street Canyons for Building Energy Simulation in Urban Context." Urban Climate 16: 75-85. https://doi.org/10.1016/j.uclim.2015.12.003.

Doya, Maxime, Emmanuel Bozonnet, and Francis Allard. 2012. "Experimental Measurement of Cool Facades' Performance in a Dense Urban Environment." Energy and Buildings 55: 42-50. https://doi.org/10.1016/j.enbuild.2011.11.001.

Edwards, B, M Sibley, P Land, and M Hakmi. 2006. Courtyard Housing: Past, Present and Future. Taylor \& Francis.

Gebhart, B. 1961. "Surface Temperature Calculations in Radiant Surroundings Ofarbitrary Complexity -for Gray, Diffuse Radiation." Int. J. Heat Mass Transfer 3: 341-46.

Gros, Adrien, Emmanuel Bozonnet, and Christian Inard. 2014. "Cool Materials Impact at District Scale Coupling Building Energy and Microclimate Models." Sustainable Cities and Society 13: 25466. https://doi.org/10.1016/j.scs.2014.02.002.

Hagishima, Aya, and Jun Tanimoto. 2003. "Field Measurements for Estimating the Convective Heat Transfer Coe Cient at Building Surfaces" 38: 87381. https://doi.org/10.1016/S0360-1323(03)000337.
Harman, IANN, Janet F Barlow, and Stephen E Belcher. 2004. "Scalar Fluxes from Urban Street Canyons. Part Ii: Model," 387-409.

Klein, S.A., W.A. Beckman, J.W. Mitchell, J.A. Duffie, N.A. Duffie, T.L. Freeman, J.C. Mitchell, et al. 2010. TRNSYS 17: A Transient System Simulation Program. Madison, USA: Solar Energy Laboratory, University of Wisconsin.

Kusuda, T., and P.R. Achenbach. 1965. "Earth Temperatures and Thermal Diffusivity at Selected Stations in the United States." ASHRAE Transactions, no. 71(1): 61-74. http://www.dtic.mil/dtic/tr/fulltext/u2/472916.pdf.

Malet, M. L. 1983. "Air Pollution Modeling and Its Application." Eos, Transactions American Geophysical Union 64 (52): 1008. https://doi.org/10.1029/EO064i052p01008.

Musy, Marjorie, Laurent Malys, Benjamin Morille, and Christian Inard. 2015. "The Use of SOLENEMicroclimat Model to Assess Adaptation Strategies at the District Scale." Urban Climate 14: 213-23. https://doi.org/10.1016/j.uclim.2015.07.004.

Robinson, Darren, Frédéric Haldi, J. Kämpf, Philippe Leroux, Diane Perez, Adil Rasheed, and Urs Wilke. 2009. "CitySim: Comprehensive Micro-Simulation of Resource Flows for Sustainable Urban Planning." In Proc. Building Simulation, 16141627.

Soulhac, Lionel, Richard J Perkins, and Pietro Salizzoni. 2008. "Flow in a Street Canyon for Any External Wind Direction," 365-88. https://doi.org/10.1007/s10546-007-9238-X.

Tennekes, H. 1973. "The Logarithmic Wind Profile." Journal of the Atmospheric Sciences. https://doi.org/10.1175/15200469(1973)030<0234:TLWP>2.0.CO;2.

Vallati, Andrea, Andrea De Lieto Vollaro, Iacopo Golasi, Eugenio Barchiesi, and Carlo Caranese. 2015. "On the Impact of Urban Micro Climate on the Energy Consumption of Buildings." Energy Procedia 82: 506-11. https://doi.org/10.1016/j.egypro.2015.11.862.

$\mathrm{Xu}$, Xiaodong, Fenlan Luo, Wei Wang, Tianzhen Hong, and Xiuzhang Fu. 2018. "Performance-Based Evaluation of Courtyard Design in China 's ColdWinter Hot-Summer Climate Regions," 1-19. https://doi.org/10.3390/su10113950.

Zamani, Zahra, Shahin Heidari, and Pirouz Hanachi. 2018. "Reviewing the Thermal and Microclimatic Function of Courtyards." Renewable and Sustainable Energy Reviews 93 (June): 580-95. https://doi.org/10.1016/j.rser.2018.05.055. 